\title{
The Instability of Economic Systems and speculative market: The case of China.
}

\author{
Giovanni Antonio Cossiga \\ Università Sapienza Roma, Italy
}

\begin{abstract}
The paper aims to investigate instability of an economy on the threshold of a financial crisis. We will try to peek on the main variables that seem to "warn" the outbreak of a financial crisis. In fact, the bubble distorts the values of the GDP, which therefore rise. In contrast, the trend in nominal prices remains neutral, because only sensitive to the real economy. This dissonance between the values of growth and inflation can be a useful clue to decipher the formation of a bubble.

Therefore, we consider comparing the performance of both GDP and inflation in the years preceding the crisis. After will attempt to determine whether these features are sufficient, at least in part, to provide meaningful messages in a state of emergency being prepared.

In the final part of the essay, we try to apply the search procedure to today's China, which has accumulated profound abnormalities in twenty years of growth boiling. In the experience more or less recent, the formation of a massive speculative bubble is constantly accompanied by a remarkable tendency to deflation of the price system. China is perhaps repeating the experience of Japan and travels to a financial crisis of unexpected violence? We suppose that the shocks of the global economy are transferred to the Chinese giant, which reacts with a slowdown in its endless growth.
\end{abstract}

JEL: E 31

KEYWORDS: Deflation, Instability, financial Crisis, speculative Bubble, economic cycle

\section{INTRODUCTION}

The paper aims to investigate instability of an economy on the threshold of a financial crisis. An incubation period of the crisis in the making, during which an economic system, which is subjected to persistent instability, underlies to irrational exuberance (bubble) not coherent with the economic framework. The bubble is then a stage irrational, because the unstable economic system accumulates errors as an organism immune system in disarray. In an epoch of globalization, large unbalances that accumulate in the continental horizons, as well as the contagion that spread in time of financial crisis, are potentially the result of the instability that has taken possession of the development trends in major economies, especially in America and Asia.

A long period of accelerated growth can be an incubator that has caused the unstable condition. This is the case in Japan in the eighties, when the irrational exuberance was treated as a continuation of a supposed unlimited growth. More recently, in America and major European countries, the irrational exuberance of the bubble that preceded the recent financial crisis, seems to mark the unexpected end of Keynesian models to support endless the economy. 
In the experience of recent decades, the formation of speculative bubbles marked the efficiency of economies, lingering on a lower level than the potential, both in Japan in the nineties, both in the West, with the global crisis in the years 2008-2009. The performance of the economy, at the same time characteristic and sneaky (sectorial exuberance and subdued trend in the real economy), during the bubble which flows in the financial crisis, may be the key issue to investigate the status of potential crisis of a system unstable. In short, in a context dominated by the speculative bubble in some areas are generated accelerations, not only irrational but also incongruous, because they do not propagate to the entire circuit of the economy. Therefore, the cycle expands in moderate form and in any case weaker than the potential.

This behavior can be subtle, perhaps explaining the difficulty of scholars and government authorities in providing for and put a stop, even if possible, to the formation of the bubble. Salvo limited exceptions of foresight that made him famous Nouriel Roubini, in that time a countercurrent economist.

The relative ambiguity of the economic environment before the financial crisis is confirmed by an inflation rate just as moderate, even in the presence of shock on oil price. In the years that preceded the financial crisis of 2008-2009, the price of oil surpassed $\$ 150$ a barrel, from $\$ 10$ in 2001. However, the exponential growth in the price of crude oil has excited only marginally inflation in Western, a certain strange behavior and not justified in a normal condition of the economy. The inconsistent performance of the two macro-variables - bridled inflation and moderate growth - is therefore a clear and incontrovertible failure, in a context -especially in the USA- of high-excitation of the irrational real estate and exponential acceleration of credit for mortgages, engineered by creative financing (CDO, CMO's, etc.) and insurance products (CDS - credit default swap.) ${ }^{i}$.

Through these anomalies, occurring in the economy - such as irregular patterns and not justified macrovariables - you can discover, through analysis, the potential behavior of an unstable system at risk of a possible financial crisis. In fact, it seems reasonable argue that the irrational excitement (bubble), which anticipates the financial crisis, is a strategy to fix the state of instability of an economic system. A strategy that requires the quasi-obligatory passage through the irrational speculation and then the washing of the financial crisis, if the causes of instability in the system are not buffered by accepting the penalty for early return to economic stability.

In other words, the wind of irrationality is solicited by speculation that acts as a saprophyte on the body sick economy. However, the speculation is the fever but the disease is the instability of the economic system.

Economy becomes unstable when derailed from the track of stability, due to factors that may indicate generically as internal or external shocks. The engines of the instability can be many and the consequences are not the same in terms of intensity and development effects. Thus, the long period of economic growth (stable) after the war was then stranded in an equally long period of global inflation and disinflation in the seventies and eighties. Otherwise, the scorching growth of the Japanese economy ended in the eighties with the financial crisis and the prolonged deflation.

In the following pages, we will try to peek on the main variables that seem to "warn" in advance the earthquake, which is prepared by the outbreak of a financial crisis. Therefore, we consider comparing the performance of both GDP and inflation in the years preceding the crisis, using quarterly data for that record with more sensitivity to the mutual relations. After having reviewed and reported the possible anomalies in the following chapters will attempt to determine whether these features are sufficient, at least in part, to provide meaningful messages in a state of emergency being prepared. In the final part of the essay, we try to apply the search procedure to today's China, which has accumulated profound 
abnormalities in twenty years of growth boiling. China is perhaps repeating the experience of Japan and travels to a financial crisis of unexpected violence? It is possible turn around and plane to a stage of sound growth of the Chinese economy?

\section{THE INSTABILITY OF THE ECONOMY IS MEASURED?}

Recent experience shows the performance of the economy, grapples with a bubble, unexpectedly almost normal and deceitful and, ultimately, facing a severe financial crisis. This apparent regularity is a kind of anesthetic to the public and the authorities should take steps to counter the excesses. On the other hand, during acceleration irrational for specific sectors, it generates a perverse mechanism and automatic, making it more fluid, so to speak, the formation of excess while it loosen the faculties of risk assessment.

Therefore, e.g. during the formation of the bubble in U.S. housing, the supply of liquidity for the granting of new loans was amplified beyond reason by the creation of financial vehicles through securitization of mortgage loans, multi-level, offered to the public with attractive returns. It created such cash flows without stopping, which could feed parallel flow of new mortgages, loosening the rules on the creditworthiness of borrowers. For this reason, many loans granted during the year preceding the outbreak of the financial crisis are so-called subprime, that is at risk of insolvency, but packed into financial vehicles (CDOs) were considered reliable because with collateral.

Ambiguous economic data and tools spoiled that fueled sectorial bubble, were a good narcotic to continue until the stop imposed by the crisis explode. Therefore, the question is how to measure the instability of a system that hides and incubates the possible next financial crisis. In economies at risk of persistent instability, the evolution of closely related variables GDP and inflation becomes a trend breathtaking, in bursts. A singular phenomenon that cannot emerge when the economic systems are sufficiently reliable and stable and that, therefore, can be used as an indicator of the condition of unstable economy.

These specific anomalies of a highly unstable system (ambiguity of the trend variables, intimate correlation between GDP and inflation) leads to the assumption that, in systems so altered, the possibility of forecast about the trends of the two variables in question suffers a severe distortion. In other words, the ability to forecast trends could be strongly distorted because of the irregular behavior occurring in a state of persistent instability. In general terms, these irregularities and distortions of the predictive power, by definition, cannot occur when economies are in normal condition and almost stable.

To verify this hypothesis, we examined the results of two auto-regressive equations, respectively, with inflation of two delays and GDP also with two delays. Is also used as regressors some predictors: public debt relative to GDP, interest rates in the long term, the unemployment rate, the current account balance as\% of GDP, the trend in $M_{3}$ liquidity, and for each equation the variable related to two delays. Below we transcribe the two regressive equations:

$$
\begin{aligned}
& \text { - } \quad \Delta \operatorname{lnf}(\mathrm{t})=\beta_{0}+\beta_{1} \Delta \operatorname{lnf}(\mathrm{t}-1)+\beta_{2} \Delta \operatorname{lnf}(\mathrm{t}-2)+\delta_{1} \mathrm{GDP}(\mathrm{t}-1)+\delta_{2} \mathrm{GDP}(\mathrm{t}-2)+\delta_{3} \operatorname{Unemp}(\mathrm{t}-1)+\delta_{4} \operatorname{DebPub}(\mathrm{t}-1)+ \\
& \delta_{5} \text { Longterm }(\mathrm{t}-1)+\delta_{6} \mathrm{M}_{3}(\mathrm{t}-1)+\delta_{7} \text { Account }(\mathrm{t}-1)+\mathrm{u}_{\mathrm{t}} \\
& \text { - } \operatorname{GDP}(\mathrm{t})=\beta_{0}+\beta_{1} G D P(\mathrm{t}-1)+\beta_{2} \operatorname{GDP}(\mathrm{t}-2)+\delta_{1} \Delta \operatorname{Inf}(\mathrm{t}-1)+\delta_{2} \Delta \operatorname{lnf}(\mathrm{t}-2)+\delta_{3} U n e m p(t-1)+\delta_{4} \operatorname{DebPub}(\mathrm{t}-1)+ \\
& \delta_{5} \text { Longterm (t-1) }+\delta_{6} M_{3}(t-1)+\delta_{7} \text { Account }(t-1)+u_{t}
\end{aligned}
$$

It specifies that: 
- $\boldsymbol{\beta}_{0}, \beta_{1}, \beta_{2}, \delta_{1}, \delta_{2} \ldots \delta_{7}$ are unknown coefficients and calculated with use of OLS $\mathrm{GDP}_{\mathrm{t}-1}$

- $\Delta \operatorname{lnf}_{\mathrm{t}-1}$ is the dependent variable on the rate of growth (GDP)

- Unemp $_{\mathrm{t}-1}$ predictor is referred to the unemployment

- Deb.Pb $b_{t-1}$ is the predictor on the public debt in terms of GDP

- Longterm $_{\mathrm{t}-1} \quad$ is the predictor on the long-term rates

- $\mathbf{M}_{3 \mathrm{t}-1} \quad$ predictor is reported to liquidity (M3)

- Account $_{\mathrm{t}-1}$ predictor is referred to the current account in terms of GDP

For both equations (1) and (2) is added to the error correction term, specifically the VECM [Inf (t-1) $\theta \Delta$ GDP (t-1)] to regression (1) and [ $\Delta$ GDP ( $t-1)-\theta I n f(t-1)]$ in the expression (2), in the case of confirmation of the existence of a co-integration between the two series.

According to this approach, we proceed for each of the countries surveyed to establish as a priority that the two sets, "Inf ( $t$ )" and "GDP ( $t$ )", have a stochastic trend, checking with the Dickey-Fuller Test Augmented (Dickey David, Wayne Fuller, 1979) the null hypothesis of the existence of a unit root. Then we proceed to ascertain that two series have a stochastic trend.

In line with the procedure for the Dickey-Fuller test augmented (ADF), it first checks the null hypothesis $\mathrm{Ho}: \delta=0$ against the alternative unilateral $\mathrm{H}_{1}: \delta>0$ in the regression:

- $\Delta \operatorname{lnf}(\mathrm{t})=\beta_{0} \delta \Delta \operatorname{lnf}_{(\mathrm{t}-1)}+\Upsilon_{1} \Delta \operatorname{lnf}_{(\mathrm{t}-1)}+\Upsilon_{2} \Delta \operatorname{lnf} f_{(\mathrm{t}-2)}+\Upsilon_{3} \Delta \operatorname{lnf}_{(\mathrm{t}-3)}+\Upsilon_{4} \Delta \operatorname{lnf} f_{(\mathrm{t}-4)}+\mathrm{u}_{\mathrm{t}}$

On the other hand, if the alternative hypothesis is that "Inf $(t)$ " is stationary with a deterministic trend, the following regression by adding " $t$ " (number of observations), where $\alpha$ is an unknown coefficient:

$-\Delta \operatorname{lnf}(t)=\beta_{0}+a t+\delta \Delta \operatorname{lnf}(t-1)+\Upsilon_{1} \Delta \operatorname{lnf} f_{(t-1)}+\Upsilon_{2} \Delta \operatorname{lnf}(t-2)+\Upsilon_{3} \Delta \operatorname{lnf}_{(t-3)}+\Upsilon_{4} \Delta \operatorname{lnf}_{(t-4)}+u_{t}$

Similarly, we proceed to apply the ADF test to auto-regressions:

- $\Delta G D P_{t}=\beta_{0} \delta \Delta \operatorname{lnf} f_{(t-1)}+\Upsilon_{1} \Delta G D P_{(t-1)}+\Upsilon_{2} \Delta G D P_{(t-2)}+\Upsilon_{3} \Delta G D P_{(t-3)}+\Upsilon_{4} \Delta G D P_{(t-4)}+u_{t}$

- $\Delta \mathrm{GDP}_{\mathrm{t}}=\beta_{0}+a \mathrm{t}+\delta \Delta \operatorname{lnf}_{(\mathrm{t}-1)}+\Upsilon_{1} \Delta \mathrm{GDP}_{(\mathrm{t}-1)}+\Upsilon_{2} \Delta \mathrm{GDP}_{(\mathrm{t}-2)}+\Upsilon_{3} \Delta \mathrm{GDP}_{(\mathrm{t}-3)}+\Upsilon_{4} \Delta G D P_{(\mathrm{t}-4)}+\mathrm{u}_{\mathrm{t}}$

The ADF statistic is the t-statistic of OLS that verify " $\delta$ " in the regressions (3), (4), (5) and (6). Applying the ADF test to all the countries surveyed, we found confirmation that both series "Inf(t)" and "GDP(t)" for the period between 1993 and 2011 have a unit root.

Now we can pass to the second stage to determine whether the series under consideration are cointegrated among them and, therefore, we must integrate the regressions (1) and (2) by adding the VECM, as explained in detail above. Checking the presence of cointegration between the two variables must be extended naturally to each country concerned and repeated for the years in which it was formed and enlarged the speculative bubble in the housing market, and then, during the severe financial crisis that followed the irrational boom.

We can proceed to the test of co-integration EG-ADF (acronym of Engle-Granger Augmented DickeyFuller - Engle and Granger, 1987), which is the test for the existence of a unit root applied to regression of residuals ${ }^{1}$ :

\footnotetext{
1 If the co-integration coefficient is unknown, now it is necessary to estimate it before assessing the presence of a unit root. The procedure EG-ADF considers two steps. Specifically, in first step, the co-integration coefficient is obtained with the OLS regression model : $\mathrm{Y}_{\mathrm{t}}=\mathrm{a}+\vartheta \mathrm{X}_{\mathrm{t}}+\mathrm{z}_{\mathrm{t}}$.
} 


$$
Y_{t}-\theta X_{t}=z_{t} \quad \text { id est: } \quad \operatorname{lnf}_{t}-\theta G D P_{t}=z_{t}
$$

Where the expression $z_{t}$ represents the regression of the residuals and $\theta$ the Co-integration Coefficients. The existence of a cointegration relationship between the variables Gross Product and Inflation is confirmed if the following relation is satisfied:

$$
\text { Inf }_{\mathrm{t}}-\theta G D P_{t}=z_{t} \quad \text { if : } z_{t} \sim \mathrm{l}(0)-\text { (the series is stationary) }
$$

A simple estimator of $\theta$ is the DOLS (OLS dinamic - Stock and Watson, 1993). The DOLS estimator is based on a modified version from (7), which includes current and past values of $X_{t}$, as below:

$$
\operatorname{lnf}_{\mathrm{t}}=\beta_{\mathrm{o}}+\theta G D P_{\mathrm{t}}+\delta_{1} \Delta G D P_{\mathrm{t}-1}+\delta_{2} \Delta G D P_{\mathrm{t}-2} \ldots . .+\delta_{2} \Delta G D P_{t-p}+z_{t}
$$

To ascertain the possible co-integration of the two variables, the second step of test EG-ADF is still the ttest in the residuals of regression (8), as below:

$$
\Delta z_{t}=\rho * z_{t-1}+\rho_{1} \Delta z_{t-1}+\rho_{2} \Delta z_{t-2}+\ldots+\rho_{k} \Delta z_{t-k}+\varepsilon_{t} \quad \text { (residuals regression) }
$$

The test EG-ADF results are reported in endnote $\mathrm{e}^{\mathrm{ii}}$. So in the case of confirmed cointegration relationship between the two variables under consideration in the development of the regressions (1) and (2) it is added the error correction term (VECM) to the equations; specifically for the following countries: U.K., Germany, Holland, Iceland, Mexico, Japan and Korea.

At the start of the paragraph has hinted at possible changes that the predictive power of the operators may suffer during the boom times, because of the surplus liquidity in the market despite a low level of inflation in tendential decline. Well, the shortsightedness that catches the operators, due to the distortion in the behavior of key variables during the time of the boom, should reverberate even in the calculated values using the technique of pseudo-forecasts, which therefore may present similar alterations compared to real data.

This attenuation of the normal ability to predict that captures the market in periods of prolonged instability or speculative boom systems, by definition, cannot continue when the economy returns to the condition of almost stability. In other words, in a stable system the prospect of sustainable growth over time becomes a container that can shape the evolution of GDP in harmony with all other variables, starting with low inflation and the gradual decline in unemployment.

This difference between the unstable economies and economies in health - in other words the anomalous behavior of the variables that lose normal harmonious relationship between them - can represent a sort of alarm bell to the entry of a system in an area of instability. The issue is discussed later. In the meantime, we look at some countries in different areas of the world to ascertain the possible deviation of the results of the calculations forecasts compared to actual data for two variable under consideration. Let us start with the countries ( $\mathrm{few}$ ) that during the speculative boom of the last ten years have been immune or affected to a limited extent by the phenomenon.

We begin the review from Korea, which maintains a position of relative equilibrium in the economic and financial since the nineties. Were examined quarterly data for the period from 1st quarter of 1991 the 1st quarter of 2011, focusing the attention to the comparison between forecasts and actual data on the second and 3 rd quarter of 2007. This period coincides with the loss of momentum of the housing bubble and the start of the financial crisis and the worst recession since the war in the spring of 2008.

Then, in the second step, a t-test di Dickey-Fuller (with intercept but no time trend) is used to assess the presence of unit root in the residuals of this regression. 
The public debt of the country at the time was on average $25 \%$ of GDP, average inflation in the period 2003-2007 amounted to about 3\%, the economy proceeds at a fast pace in the first decade of 2000 recording an increase in GDP by an average of $4.6 \%$. The equilibrium condition of the Korean economy in the period covered by the worldwide speculative boom and subsequent global financial crisis leads to suppose that the harmonious evolution of the variables has encouraged a nearly aligned to the real data of the forecasts for both variables.

The results reported in Table 1 essentially confirm this assumption. In the same table shows, by way of comparison, the forecast data, always refer to the 3rd quarter of 2007, calculated using the same procedure for Germany, Denmark, the Netherlands and Switzerland. The Central European countries were relatively involved in the season of the housing bubble, which has spread in America and Europe up to Australia. The consequences on the real economy, therefore, come mainly from outside, also for the export orientation of the two central European countries.

Lastly, New Zealand has been less involved than the neighboring Australia in the speculative euphoria in real estate iii and has a traditional economy based on agricultural exports and the tourism industry. As can be seen in the following tables, the forecasts for these six countries report on - compared with real data - a distortion that is quite clear for Inflation and less pronounced for GDP. In terms of inflation, the difference between actual data and calculated is highest for Greece, a statistical confirmation of the serious imbalance of the Greek economy in the imminence of serious financial crisis which followed the explosion of the bubble.

In table 2, the forecasting results are reported, compared with the real data obtained by the same equations (1) and (2) ${ }^{2}$, for the quarter prior to that considered in Table 1. The results for both quarters in the observation showed appreciable symmetry of the comparison with regard to Korea, and conversely in terms of inflation the lack of reliability of comparison for the second group of countries.

Table n. 1

Comparison between the actual data of the variation in inflation and GDP in Q3 2007 and estimates calculated by the equations (1) and (2)

\begin{tabular}{|c|c|c|c|c|}
\hline \multirow[t]{2}{*}{ - } & \multicolumn{2}{|l|}{ Inflation } & \multicolumn{2}{|l|}{ GDP } \\
\hline & Forecasts & Real Data & Forecasts & Real Data \\
\hline Korea & $\begin{array}{c}0,455 \\
R^{2}=0,457 \text { Stat } F=1,685\end{array}$ & 0,67 & $\begin{array}{c}0,59 \\
R^{2}=0,258 \text { Stat } F=0,696\end{array}$ & 0,95 \\
\hline New Zealand & $\begin{array}{c}1,45 \\
R^{2}=0,678 \text { Stat } F=1,874\end{array}$ & 0,49 & $\begin{array}{c}1,16 \\
R^{2}=0,440 \text { Stat } F=0,699\end{array}$ & 0,45 \\
\hline Germany & $\begin{array}{c}1,04 \\
R^{2}=0,327 \text { Stat } F=0,970\end{array}$ & $-0,23$ & $\begin{array}{c}-0,04 \\
R^{2}=0,647 \text { Stat } F=3,663\end{array}$ & 0,80 \\
\hline Denmark & $\begin{array}{c}1,08 \\
R 2=0,470 \text { Stat } F=1,773\end{array}$ & $-0,38$ & $\begin{array}{c}0,94 \\
R 2=0,446 \text { Stat } F=1,608\end{array}$ & 1,09 \\
\hline Netherlands & $\begin{array}{c}0,37 \\
R_{2}=0,394 \text { Stat } F=1,298\end{array}$ & $-0,41$ & $\begin{array}{c}0,57 \\
R 2=0,606 \quad \text { Stat }=3,078\end{array}$ & 1,16 \\
\hline Switzerland & $\begin{array}{c}2,54 \\
R 2=0,834 \text { Stat } F=10,49\end{array}$ & $-0,48$ & $\begin{array}{c}0,96 \\
R_{2}=0,627 \text { Stat }=3,355\end{array}$ & 0,94 \\
\hline
\end{tabular}

${ }^{2}$ Adding the error correction term (VECM) to the equations, when necessary. 
Table n. 2

Comparison between the actual data of the variation in inflation and GDP in Q2 2007 and estimates calculated by the equations (1) and (2)

\begin{tabular}{|c|c|c|c|c|}
\hline & \multicolumn{2}{|l|}{ Inflation } & \multicolumn{2}{|l|}{ GDP } \\
\hline & Forecasts & Real Data & Forecasts & Real Data \\
\hline Korea & $\begin{array}{ll}1,082 & R^{2}=0,476 \quad \text { Stat } F=1,717\end{array}$ & 1,06 & $\begin{array}{c}0,99 \\
R^{2}=0,317 \text { Stat } F=0,877\end{array}$ & 1,39 \\
\hline New Zealand & $\begin{array}{c}1,04 \\
R 2=0,611 \text { Stat } F=2,961\end{array}$ & 0,99 & $\begin{array}{c}0,83 \\
\mathrm{R} 2=0,409 \text { Stat } F=1,387\end{array}$ & 1,59 \\
\hline Germany & $\begin{array}{c}0,508 \\
R 2=0,351 \text { Stat } F=1,021\end{array}$ & $-0,07$ & $\begin{array}{c}0,66 \\
\mathrm{R} 2=0,689 \text { Stat } F=4,182\end{array}$ & 0,32 \\
\hline Denmark & $\begin{array}{c}-0,19 \\
R 2=0,484 \text { Stat } F=1,768\end{array}$ & 0,91 & $\begin{array}{c}1,83 \\
R 2=0,601 \text { Stat } F=2,85\end{array}$ & $-0,85$ \\
\hline Netherlands & $\begin{array}{c}-0,08 \\
R 2=0,5 \text { Stat } F=1,889\end{array}$ & 1,27 & $\begin{array}{c}1,13 \\
\mathrm{R} 2=0,348 \text { Stat } F=2,910\end{array}$ & 0,53 \\
\hline Switzerland & $\begin{array}{c}-1,44 \\
R 2=0,862 \text { Stat } F=11,78\end{array}$ & 1,45 & $\begin{array}{c}0,89 \\
\mathrm{R} 2=0,611 \quad \text { Stat }=2,978\end{array}$ & 0,95 \\
\hline Greece & $\begin{array}{c}-2,19 \\
\mathrm{R} 2=0,864 \text { Stat } F=12,04\end{array}$ & 1,86 & $\begin{array}{cc}1,59 & \\
\mathrm{R} 2=0,176 \quad \text { Stat }=0,404\end{array}$ & 0,46 \\
\hline
\end{tabular}

Elaborations on data OCSE da "OECD.Stat Extracts

I note also that the data estimates are much closer to the real result, both inflation and the GDP, the higher the equilibrium and stability of the economic system. Similarly, the magnitude of the differences that occur between forecasts and actual data are evidence of a high degree of instability.

Now let us examine the behavior of the usual variables in relation to economies that, within this period, showed a strong acceleration for specific sectors (bubble), for which they have been hit hard by the financial crisis in 2008-2009. I refer in particular to the United States, Britain, France, Spain and Australia.

In situations of high instability degenerated into an intense speculative bubble, it can hypothesize that the evolution of GDP, a slight increase, might have hidden, at least in part, the fragile state of the real economy, close to the financial crisis. In other words, the economy is pushed upward, essentially in virtual terms, through the improper mechanism of the bubble, providing a false impression of normality that hides the recessive real tendency of the system unstable. Unexpectedly, then, with the help of virtual component, growth could "mislead" the estimates calculated by the equations (1) and (2), precisely because it remains relatively small in economic systems with a speculative bubble in progress. In essence, the trend of economic growth, equivocally normal in these very unstable systems may paradoxically adjust (wrongly) the forecast calculation.

Otherwise, the calm performance of the variable "inflation" should continue to show a forecast unreliable. The virtual nature of the economic growth it should not influence the course of the price system, which remains in effect subject to the economic trend (in really) recessive. In this context, the deflationary trend in prices tapering the rate of structural inflation that the system had previously accumulated. The forecast should then indicate higher inflation, because the virtual growth pushed by the bubble influences the calculation of the price trend. 
To test this hypothesis have been applied regressions (1) and $(2)^{3}$, to calculate expected values for Inflation and GDP, again with reference to the 2nd and 3rd quarter of 2007, for the countries above mentioned on the eve of a financial crisis of comparable intensity to that of the thirties. We have examined the series of quarterly data for the period from January 1991 to 3 rd quarter 2007, the period during which originated and then inflated the bubble in real estate.

In table 3, the results of these calculations are presented in comparison with the real values of Inflation and GDP, relative to the third quarter of 2007. In the following Table 4 the comparison is extended to the previous quarterly period.

Reading the two Tables 3 and 4, the sufficient quality of estimates in terms of GDP and the inadequacy of that on inflation appear confirmed. Specifically, the estimates in terms of GDP, correct cross-eyed, is not surprising because it's counterpart with the ambiguity of the pre-financial crisis. The context is so alienating, because the game too sober of economic growth and the "calmness" on inflation developments make it likely that the ability of individual perception of risk can be blurred in a deceptive sort of nirvana.

Tables 3 and 4, in addition to the 7 aforementioned countries, also includes three countries, Italy, Belgium and Japan. Countries little or not involved in the vortex of the bubble but hit by depression and financial crisis that followed because of the heavy baggage of debt. Financial instability for excessive public debt assimilates them - in terms of results of the regressions - to the countries most prone to speculative effervescence.

Table n. 3

Comparison between the actual data of the variation in inflation and GDP in Q3 2007 and estimates calculated by the equations (1) and (2)

\begin{tabular}{|c|c|c|c|c|}
\hline \multirow[b]{3}{*}{ USA } & \multicolumn{2}{|l|}{ Inflation } & \multicolumn{2}{|l|}{ GDP } \\
\hline & Forecasts & Real data & Forecasts & Real data \\
\hline & $\begin{array}{c}1,35 \\
R^{2}=0,633 \text { Stat } F=3,456\end{array}$ & 0,28 & $\begin{array}{c}0,34 \\
R^{2}=0,460 \text { Stat } F=1,707\end{array}$ & 0,56 \\
\hline U. K. & $\begin{array}{c}1,80 \\
R^{2}=0,794 \text { Stat } F=7,729\end{array}$ & $-0,13$ & $\begin{array}{c}0,44 \\
R^{2}=0,343 \text { Stat }=0,941\end{array}$ & 0,53 \\
\hline Spain & $\begin{array}{c}3,27 \\
R^{2}=0,841 \text { Stat } F=10,59\end{array}$ & $-0,32$ & $\begin{array}{c}0,81 \\
R^{2}=0,699 \text { Stat } F=4,695\end{array}$ & 0,7 \\
\hline France & $\begin{array}{c}1,13 \\
R 2=0,550 \text { Stat } F=2,443\end{array}$ & 0,22 & $\begin{array}{c}0,46 \\
R 2=0,433 \text { Stat } F=1,528\end{array}$ & 0,65 \\
\hline Australia & $\begin{array}{c}1,86 \\
R 2=0,698 \text { Stat } F=4,615\end{array}$ & 0,70 & $\begin{array}{c}1,11 \\
R 2=0,520 \text { Stat } F=2,166\end{array}$ & 0,39 \\
\hline Italy & $\begin{array}{c}0,87 \\
R 2=0,801 \text { Stat } F=8,067\end{array}$ & 0,58 & $\begin{array}{c}0,04 \\
R 2=0,396 \text { Stat } F=1,310\end{array}$ & 0,20 \\
\hline Belgium & $\begin{array}{c}0,40 \\
R 2=0,411 \text { Stat } F=1,398\end{array}$ & 0,56 & $\begin{array}{c}2,91 \\
R 2=0,948 \text { Stat } F=36,79\end{array}$ & 2,99 \\
\hline
\end{tabular}

\footnotetext{
${ }^{3}$ Adding the error correction term (VECM) to the equations, when necessary
} 


\begin{tabular}{|l|c|c|c|c|}
\hline Japan & 0,35 & $-0,27$ & 0,66 & $-0,01$ \\
& $R 2=0,365$ Stat $F=1,151$ & & $R 2=0,649$ Stat $F=3,697$ & \\
\hline
\end{tabular}

Table n. 4

Comparison between the actual data of the variation in inflation and GDP in Q2 2007 and estimates calculated by the equations (1) and (2)

\begin{tabular}{|c|c|c|c|c|}
\hline & \multicolumn{2}{|l|}{ Inflation } & \multicolumn{2}{|l|}{ GDP } \\
\hline & Forecasts & Real data & Forecasts & Real data \\
\hline USA & $\begin{array}{c}1,75 \\
R^{2}=0,625 \text { Stat } F=3,148\end{array}$ & 1,92 & $\begin{array}{c}0,35 \\
R^{2}=0,544 \text { Stat } F=2,260\end{array}$ & 0,80 \\
\hline U. K. & $\begin{array}{c}-0,33 \\
R^{2}=0,786 \text { Stat } F=6,958\end{array}$ & 1,03 & $\begin{array}{c}0,89 \\
R^{2}=0,354 \text { Stat } F=1,036\end{array}$ & 0,56 \\
\hline Spain & $\begin{array}{c}-0,97 \\
R^{2}=0,865 \text { Stat } F=12,12\end{array}$ & 2,16 & $\begin{array}{c}0,99 \\
R^{2}=0,699 \text { Stat } F=4,378\end{array}$ & 0,80 \\
\hline France & $\begin{array}{c}0,53 \\
R 2=0,606 \text { Stat } F=2,733\end{array}$ & 1,04 & $\begin{array}{c}1,59 \\
R 2=0,433 \text { Stat } F=1,444\end{array}$ & 0,49 \\
\hline Australia & $\begin{array}{c}1,813 \\
\mathrm{R} 2=0,686 \text { Stat } F=4,127\end{array}$ & 1,22 & $\begin{array}{c}1,274 \\
R 2=0,512 \text { Stat } F=1,985\end{array}$ & 1,30 \\
\hline Italy & $\begin{array}{c}0,88 \\
\mathbf{R} 2=0,801 \text { Stat } F=7,633\end{array}$ & 0,64 & $\begin{array}{c}0,64 \\
R 2=0,387 \text { Stat } F=1,192\end{array}$ & 0,06 \\
\hline Belgium & $\begin{array}{c}1,43 \\
R 2=0,423 \text { Stat } F=1,383\end{array}$ & 0,58 & $\begin{array}{c}2,90 \\
R 2=0,948 \text { Stat } F=34,47\end{array}$ & 3,11 \\
\hline Japan & $\begin{array}{c}-0,56 \\
\mathrm{R} 2=0,371 \text { Stat } F=1,112\end{array}$ & 1,00 & $\begin{array}{c}1,01 \\
R 2=0,683 \text { Stat } F=4,064\end{array}$ & 0,23 \\
\hline
\end{tabular}

Elaborations on data OCSE da "OECD.Stat Extracts"

To avoid this deceptive ataraxia, therefore, attention must focus on the inflation variable that is not involved by the swirl of the bubble, and thus tends to diminish over time without equivocation or, at least, to remain neutral notwithstanding the intense excitement on prices commodity. This unavoidable trend of inflation, because of its peculiarity compared to the behavior of other major variables, it is not properly evaluated by regression analysis. Therefore, in a highly unstable economic context, inflation calculated in this way remains distant from the real one. This discrepancy between the forecasts for inflation in some way clarifies the mystifying role played by other variables. However, let us look more closely at the phenomenon.

During the compulsive stage preceding the financial crisis, the evidence shows that adding two different trends. The first is related to the rise in the economic cycle, relatively weak in spite of the tension created by the bubble. A weak cycle because it is the result of the recession trend, typical of an unstable system, with the addition of the abnormal acceleration created by the bubble, which only partially spreads to the entire economy.

The second trend relates inflation, which gradually reduces due to the influence on the price system of the cyclical trend of deflation, in a high unstable economy. The cycle, net of the bubble, is recessive and 
induces a negative cyclical inflation, which depresses structural inflation. The combination of the two parallel cycles (the economy and the cyclical inflation) apparently dims, because growth (sober) in the economy is compared with the decline in inflation that remains neutral with regard to speculative excitement.

As we have said, it must however consider that the virtual part of the growth due to the bubble cannot influence the general trend of prices, which instead is sensitive almost exclusively to the underlying trend (recessive) of the real economy. A proper comparison between the two variables should therefore compare the performance of the economy, ignoring the virtual part, and the value of inflation trends. As amended, the comparison regains its consistency with both variables moving into negative territory. About the value of the virtual economic growth tied to the speculative bubble, we must consider that is a value only temporary, which the financial crisis looming will remove without residue.

In other words, while inflating the bubble, it creates an asymmetry, apparent and temporary, between the movement of the sober economic growth and the cyclical inflation profile eccentric (negative). An eccentricity that makes the inflation profile inconsistent with to the other variables and yet not predictable by the regression equations.

The dissimulation of the variables that it create in the economy during the period preceding the financial crisis is not outright misleading, because at least the structural trend of inflation (declining gradually) complaint that the system is highly unstable.

\section{5. - THE ACCELERATION OF DEVELOPMENT IS A LEAVEN FOR THE BUBBLE? THE CASE OF CHINA.}

In the following pages, it start the use of synthetic instrumentation previously delineated to make information about the performance awaited in the coming years in China. The hypothesis that will be tested in brief is the following: the continuous and accelerated economic development of the large Asian country, an average of almost $9 \%$ a year, can be considered per se a cause of a persistent instability of the economy China. In this case, it is likely the hypothesis that, in a ferment of abnormal development, this exceptional state can hide the formation of a massive speculative bubble that could explode in the coming years.

It's easy at this point recall the analogy with Japan, which since the sixties at the end of the eighty raced at breakneck speed on the road to accelerated development, at an annual rate not far from the Chinese ( $7 \%$ per annum). It was then stalled with the outbreak of a huge bubble with the tail of a never-ending financial crisis. A parallel abruptly between the two realities, however, does not seem acceptable, especially because the reproduction of extreme events in the same cliché, in a space of time and geographical neighbor, is relatively unreliable.

However, this does not mean that the Chinese economy is hatching a speculative bubble, which moreover would be at least in part the lubricant of the unusual values of its accelerated development. However, let us see what evidence, with prudence, we can put in place to support the assumption that the acceleration of the abnormal growth of the Chinese economy is per se a characteristic feature of a system turns out that, along with its rapid trend, promotes the formation of a bubble.

First, we must consider that a typical indicator of the degree of instability of an economy struggling with a speculative bubble is the singular behavior of inflation. In the experience more or less recent (e.g. U.S. and Japan), the formation of a massive speculative bubble is, contrary to expectations, constantly accompanied by a remarkable tendency to deflation of the price system. The trend of deflation it occurs during the developmental phase of the bubble, with a gradual decline in inflation that the system inherited from the past. In Japan, inflation in the early eighties was higher than the $7 \%$, drops to less 
than $1 \%$ in 1988 to go up a couple of points during the explosive phase of the bubble. Similar trends in the United States, inflation at $2 \%$ in 2006, then rises to $4 \%$ in 2007 under the incandescence rise in oil prices, only to fall almost to zero in 2008 under the blows of the crisis.

Now in the case of China the price curve shows a clear downward trend, so that it approximates to zero in early 2000, with a mild revival in 2007 under the stimulus of international prices of raw materials in high tension. The pickup in inflation in 2010 is due mainly to tensions in the prices of raw materials.

\section{Graph n. 4}

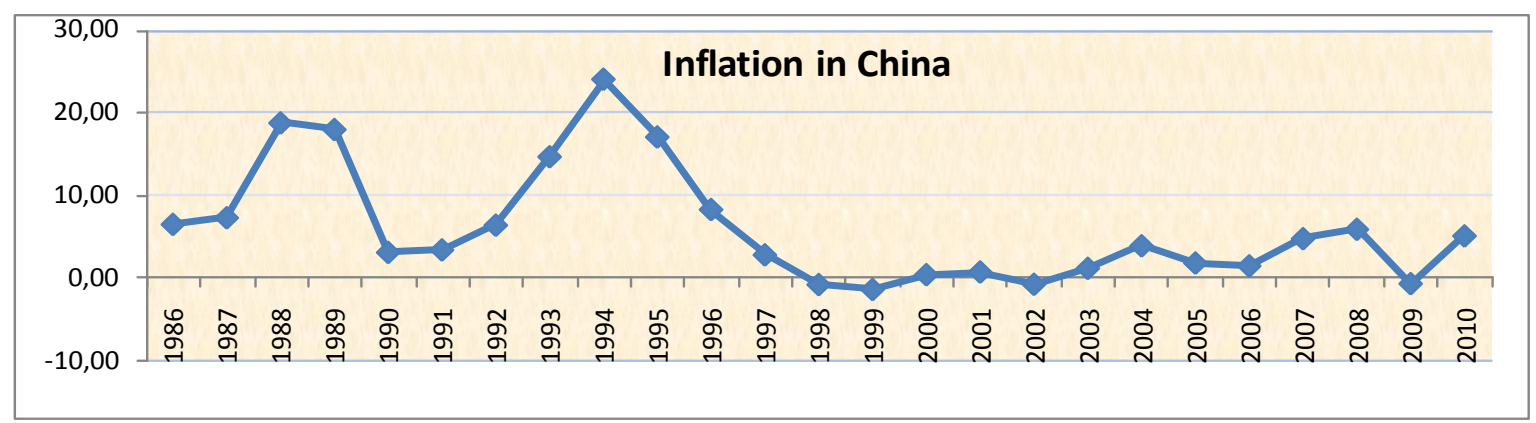

- Elaborations on data OCSE da "OECD.Stat Extracts

Obviously, the marked trend towards disinflation of the system is not a sufficient indicator to confirm the ongoing training of a speculative bubble in China. So let us examine the behavior of the two key variables, following the procedure taken in the previous paragraph. As mentioned, the unstable economies subject to speculative boom, in particular suffer from abnormalities in the behavior of the two variables, GDP and inflation. These abnormalities are quite characteristic in systems subject to speculative bubbles; because it seems to miss the usual convergence of the two variables that occur in an economy became unstable.

As we have explained, this dissonance is temporary and is the singular discrepancy produced by the virtual economy created by the bubble. In fact, the bubble distorts the values of the GDP, which therefore rise to a virtual step. In contrast, the trend in nominal prices remains neutral, because only sensitive to the real economy. As explained, this dissonance between the values of growth and inflation can be a useful clue to decipher the formation of a bubble in an economy for a long time unstable.

If the system supports the formation of a bubble, the forecast data calculated by equation 1) and 2) turn out to be enough reliable, in comparison with real data, for GDP, and are largely unreliable in terms of inflation In this regard, recall what I have observed in the previous paragraph.

In order to verify the hypothesis that China is grappling with the formation of a bubble, therefore it have used the equations 1) and 2) to calculate the estimates data, always on a quarterly basis, for the evolution of GDP and Inflation, to be compared with actual data. For the peculiarities of the economic structure of China it is considered to make some changes to the two equations 1) and 2), including predictors "Export " and "Shareprice" in place of "Public debt" and "Account" in\% of GDP

The result of the comparison is represented by the graphs No. 5, in which it confronts, separately, forecasts and actual data for the variables "GDP" and "Inflation" for the entire period, from the 2nd quarter of 2006 and the 4th quarter of 2009. By extending the comparison to 15 quarters, we try to check the progress of dynamic lines created from the data estimates for each of the two variables in China during a four-year period in which it is inflated the speculative wave in Western Europe, to then collapse in a severe financial crisis. 
Therefore, we repeated the experiment described above under the same conditions, however, reported the period 1997-2001. A five-year period during which, in America, the strong economic development of the Clinton era was followed by the new economy bubble and crisis. The results are presented with the chart n.6. The periods chosen, therefore, both are marked by a phase of growth for the world economy that predicts the financial crisis. The obvious goal is to ascertain the behavior of the Chinese economy during the period of strong growth in the global economy and, subsequently, at a time of crisis, with declining production and global trade.

\section{Graphs n. 5}

Comparison between actual data and estimates with the equations 1) and 2), amended, regarding the performance of GDP and inflation in China during the 2nd 2006 to 4th quarter 2009

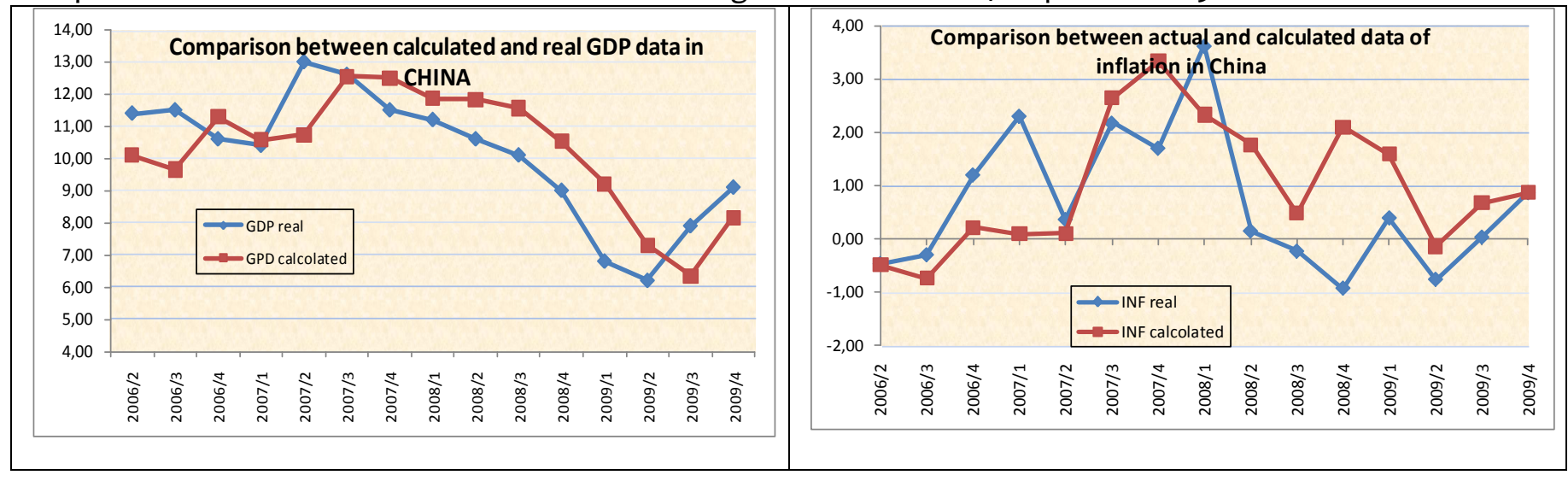

\section{Graphs n. 6}

Comparison between actual data and estimates with the equations 1) and 2), amended, regarding the performance of GDP and inflation in China during the 4th quarter 1997 to 2nd quarter 2001

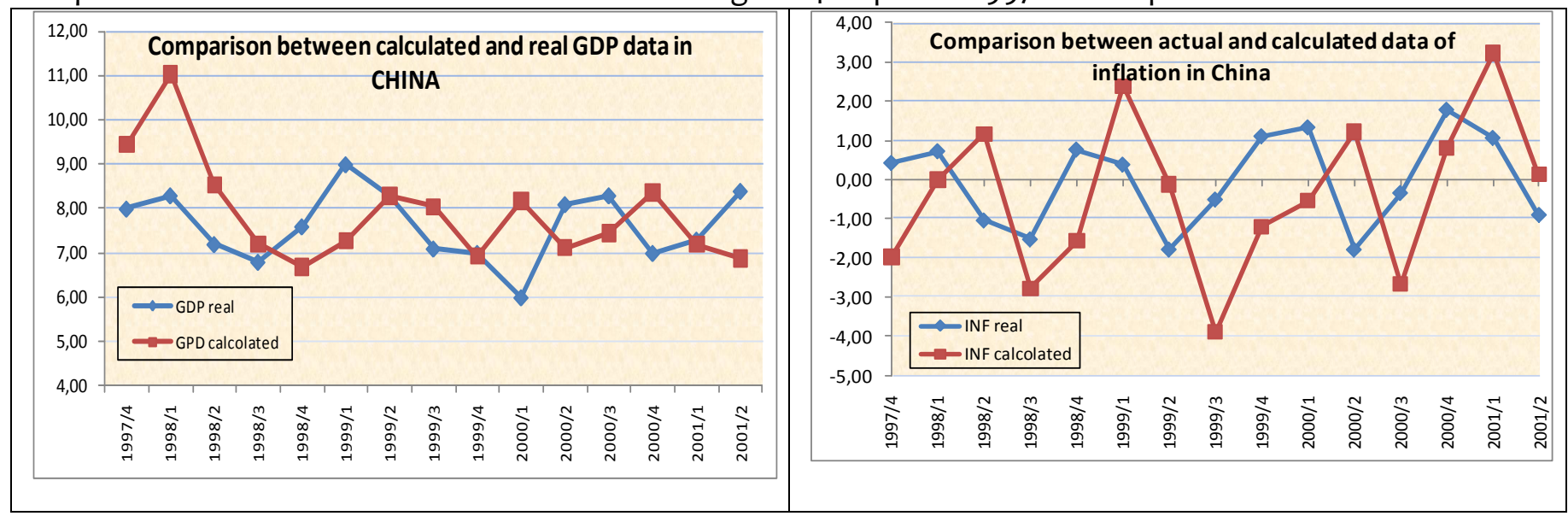

- Elaborations on data OCSE da "OECD.Stat Extracts

To provide a summary assessment of the comparison, we calculated the average absolute difference between forecasts and actual data, to see if there is a relatively small deviation of the average for GDP as opposed to a larger average size of the gaps for inflation.

We are looking for if, in the entire period, there is concrete evidence that the Chinese economy is incorporating the formation of a massive speculative bubble. This hypothesis was partly confirmed when the order of the differences is minimal for the GDP and higher for inflation. 
In reality, the calculation of average deviation does not confirm this hypothesis. In fact, the average gap for the two periods under review for the GDP is between 1.1 and 1.2, while for inflation is between 1 and 1.9. Therefore, nearly a decade in the period under review does not show a clear differentiation of the behavior of the forecasts for both variables, which each have an average low reliability. There are clear signs of unstable economy; however, signals are insufficient for a reliable assessment about the phenomenon of the speculative bubble in China.

A review in detail, however, may provide some more clarification. It is noted so that during 2007 and early 2008 are gathering estimates, very close to actual data for the GDP variable. The same phenomenon on the coincidence of the estimates of product repeats in the middle of 1998 and 1999. In other words, during the peak of the formation of speculative bubbles in the West, the growth of the Chinese economy goes up to the maximum (in 1998 suffers from a severe crisis in Southeast Asia) so that in real terms is approaching the values of the forecasts. The gap between forecasts and actual data grows worse, however, during the financial crises that affect the Western area.

The meaning of this alternate behavior, more or less close to the forecast data on GDP, seems to be related to the effects of global crisis on the vibrant growth of the Asian giant. During periods of severe global crisis, the Chinese economy slows down his march. It might seem that these phases of calmness may be sufficient at least in part to activate the natural mechanism of correction of the instability, although the results are obviously limited. The recovery in the global economy it is relatively fast, so the decline in Chinese growth lasts relatively little time, because the natural correction may perform substantially the work of rehabilitation of the altered system. With the recovery, growth returns to high values and create new conditions for convergence of the forecasts of trend GDP to actual results.

Trying to interpret these movements, it can be argued that the temporary slowdown of China's development, in essence, temporarily mitigate the instability of the system and can decompress the bubble, whose formation would then be decelerated. In other words, the shocks of the global economy are transferred to the Chinese giant, which reacts with a slowdown in its endless growth, with the good result especially to restrain the irrational emphasis, which is swelling, hypothetically, the speculative bubble. Unexpectedly, the panting development of economic growth worldwide, but primarily in the United States, appears to act as a brake on the expansion of the Chinese bubble, when the global economy impacts in a speculative crisis.

The conclusions, of course sure problematic, we have achieved on the state of the Chinese economy certainly confirm the unstable condition of the economic system of China. Are inconclusive on the hypothesis of a massive speculative bubble in progress, as the final stage of the long path of accelerated economic growth.

Moreover, on the domestic front the danger inherent in the possible formation of a bubble seems to be a serious concern for the Chinese authorities. It has been decided on a reduction in economic growth from $9.5 \%$ a year, planned for the past five years, the programmed $7.5 \%$ per year since 2010, as updated in the new 11th Five-Year Plan. Somehow, the careful direction of the Chinese nomenclature seems to capture the link between instability and the twenty-year growth at breakneck speed, and then accepts a slowing of the accelerated development to ensure compatibility in future years.

Speculation in real estate in major urban areas has reached a worrying level, the banking sector of the huge country is not under full central control and the gradual change of gear in the economic development in favor of domestic consumption requires profound changes, not least with reflections on the relationship of long-standing Dollar - Yuan. It is now on the ropes, for the Chinese economy the miracle of the twenty-year growth, at breakneck speed? 


\section{CONCLUSION}

In the experience of recent decades, an economic system develops an instability if the growth process is forced, in an attempt to accelerate the development, beyond the potential. The reaction to the instability of economic systems, in view of the return to stable condition, is cautious, even slow. The instability can last for years, before the unstable system is subject to the correction of a financial crisis, with the Schumpeterian "creative destruction" that cleans the economy of excess. With time goes, the system becomes increasingly unstable, so that it produces the favorable conditions to an acceleration of the economy speculative, driven by transgressive risk assessment. The emphasis speculative accentuates the difference between the apparent economy, enhanced by the bubble, and the real economy under-tone, until the outbreak of a financial crisis of great magnitude that sweeps away the abnormal excesses.

\section{REFERENCES}

BEN S. BERNANKE,

"Essays on the Great Depression" Princeton University Press Princeton, New Jersey - 2000

Thomas F. CARGILL, "The political economy in Japanese monetary policy" HUTCHISON, TAKATOSHY Massachusetts Institute of Technology 1997

Giovanni COSSIGA -

“Un approccio alla teoria dell'inflazione" - Rivista Milanese di economia - 2001 n. 71-72 anno 1999, Milano, Cariplo - Laterza

“Un sistema instabile, inflazionato o deflazionato. L'inflazione e il debito pubblico" in corso di pubblicazione, disponibile su richiesta (g.cossiga@alice.it)

David DICKEY, Wayne FULLER “Distribution of the Estimators for Autoregressive Time Wayne Fuller Series with an Unit Root" in Journal of American Statistical Association - (1979)

DORNBUSCH, FISCHER“ “Moderate Inflation.” 1993. World Bank Economic Review 7, 1-44

R. ENGLE - Clive GRANGER: "Cointegration and Error Correction: Representation, Estimation and Testing." Econometrica 55(2)

Timothy F. GEITHNER

"STRESS TEST -Reflections on Financial Crises" - RH Business Books

Friedman MILTON

"On economics - Selected Papers" (University of Chicago Press, 2007

Charles KINDLEBERGER “The World in Depression: 1929-1939" (University of California Press, 1973)

Paul R. KRUGMAN

"The return of depression economics and the crisis 2008" W.W. Norton \& Company, Inc. New York

"End This Depression Now"

W.W. Norton \& Company, Inc. New York

"Thinking about the liquidity trap" From : Journal of the Japanese and International Economies -221-237 (2000)

INQUIRY REPORT

"THE FINANCIAL CRISIS" - Final report of the NATIONAL COMMISSION on the causes of the financial and economic crisis in the united states - Official Edition

Leon N. LINDBERG, S. Brian BARRY

"The Politics of Inflation and Economic Stagnation" MAIER, Brookings Institution - Washington D.C. 
"Crisis Economics: A crash Course in the Future of Finance" Stephen MIHM

Nouriel ROUBINI, A. ALESINA, G. COHEN

J. Patrick RAINES, G. LEATHERS

Carmen. REINHART Kenneth S. ROGOFF

A. Gary SHILLING

Stephen S. ROACH

JH Stock, MW Watson

Peter TEMIN

Nicholas WAPSHOTT

IMF e OECD
"Political Cycles and the Macroeconomy "

"Debt, Innovation and Deflation: The Theories of Fisher, Charles Schumpeter and Minsky"-Edward.Elgar Massachusetts USA

"The Time Is Different - Eight Centuries of Financial Folly" Princeton University -Press-Princeton and Oxford- 2009

"Deflation. How survive and thrive in coming wave of deflation" 2001

"The next Asia- Opportunities and challenges for a new globalization" - John Wiley \& Sons, Inc - 2009

"A simple estimator of cointegrating vectors in higher order integrated systems" Econometrica: Journal of the Econometric Society - 1993 - JSTOR

"Lessons from the Great Depression" The MIT Press Cambridge - Massachusetts

"KEYNES - HAYEK The Clash that Defined Modern Economics" WW Norton \& Company - New York \& London

"International Financial Statistics" - Database, vari anni

"OECD. Stat - Database, vari anni

\section{ENDNOTES}

Collateralized debt obligations (CDOs) are a type of structured asset-backed security (ABS) whose value and payments are derived from a portfolio of fixed-income underlying assets. Mortgage backed securities (CMO's) are specifically backed by mortgages from a regulated and authorized financial institution. The credit default swap (CDS) is a swap that has the function to transfer the credit exposure of fixed-income products between parties. 


\begin{tabular}{|c|c|c|c|c|}
\hline Countries & $\begin{array}{l}\text { ADF test } \\
\text { results for } \\
\text { checking the } \\
\text { null hypothesis } \\
\text { of unit root }\end{array}$ & $\begin{array}{c}\text { Critical } \\
\text { values of EG- } \\
\text { ADF test at } \\
\text { the } 5 \%\end{array}$ & $\begin{array}{l}\text { Statistic } \\
\text { F values }\end{array}$ & $\begin{array}{c}\text { Reporting } \\
\text { periods }\end{array}$ \\
\hline U.K. * & $-3,865$ & $-3,41$ & 7,966 & $2001 / 2-2010 / 3$ \\
\hline USA & $-2,025$ & “ & 2,483 & $2001 / 2-2010 / 3$ \\
\hline Germany * & $-3,540$ & “ & 7,486 & $2001 / 2-2010 / 3$ \\
\hline France & $-2,647$ & “ & 2,877 & $2001 / 2-2010 / 3$ \\
\hline Italy & $-3,381$ & “ & 13,137 & $2001 / 2-2010 / 3$ \\
\hline Denmark & $-2,514$ & “ & 2,992 & $2001 / 2-2010 / 3$ \\
\hline Netherlands * & $-3,238$ & “ & 6,104 & $2001 / 2-2010 / 3$ \\
\hline Greece & $-2,132$ & “ & 3,572 & $2001 / 2-2010 / 3$ \\
\hline Switzerland & $-2,079$ & “ & 2,045 & $2001 / 2-2010 / 3$ \\
\hline Iceland * & $-\mathbf{3 , 5 4 0}$ & “ & 7,486 & $2001 / 2-2010 / 3$ \\
\hline Mexico * & $-4,126$ & “ & 4,374 & $2001 / 2-2010 / 3$ \\
\hline New Zealand & $-0,850$ & “ & 0,354 & $2001 / 2-2010 / 3$ \\
\hline Australia & $-1,826$ & “ & 0,909 & $2001 / 2-2010 / 3$ \\
\hline Japan * & $-4,592$ & “ & 28,876 & $2001 / 2-2010 / 3$ \\
\hline Korea * & $-3,516$ & “ & 4,669 & $2001 / 2-2010 / 3$ \\
\hline
\end{tabular}

* Countries linked by a co-integration relationship

iii The table below, taken by the Economist, gives evidence of the percentage change in house prices in the over ten-year period 1997-2008. 
The Economist's house-price indicators $\%$ change

\begin{tabular}{|c|c|c|c|}
\hline & Latest & Q1 2007 & \\
\hline & on aye & ar eartier & or latest \\
\hline Singapore & 29.8 & 13.8 & na \\
\hline Hong Kong & 28.2 & 5.6 & -23 \\
\hline Australia & 13.8 & 9.6 & 174 \\
\hline Sweden & 11.3 & 8.0 & 150 \\
\hline China & 10.7 & 5.6 & па \\
\hline Belgium & 7.5 & 10.0 & 147 \\
\hline South Africa & 6.8 & 15.6 & 401 \\
\hline New Zealand & 6.5 & 11.7 & 125 \\
\hline Canada & 5.7 & 9.6 & 80 \\
\hline France & 5.7 & 8.1 & 151 \\
\hline Italy & 5.1 & 5.6 & 102 \\
\hline Spain & 3.8 & 7.2 & 195 \\
\hline Netherlands & 2.5 & 4.3 & 99 \\
\hline United States (OFHEO) & nīl & 4.4 & 92 \\
\hline Switzerland & 0.5 & 2.5 & 19 \\
\hline Denmark & 0.3 & 10.0 & 124 \\
\hline Japan & -0.7 & -1.5 & -33 \\
\hline Britain & -1.0 & 9.5 & 202 \\
\hline Germany & -4.7 & 0.6 & na \\
\hline Ireland & -8.9 & 9.2 & 220 \\
\hline $\begin{array}{l}\text { United States } \\
\text { (Case-Shiller national index) }\end{array}$ & -8.9 & -1.7 & 104 \\
\hline $\begin{array}{l}\text { United States } \\
\text { (Case-Shiller ten-city index) }\end{array}$ & -13.6 & -1.2 & 138 \\
\hline
\end{tabular}

Sources: ABSA; ESRI; Hypoport; Japan Real Estate Institute; Nationwide; Nomisma; NVM; OFHEO; Quotable Value; Stadim; Swiss National Bank; Standard \& Poor's; gowemment offices 